EPiC Series in Computing
Volume 78, 2021, Pages 159-170
Proceedings of the European Univer-
sity Information Systems Conference 2021

\title{
The Impact of the Pandemic on German Academic IT Facilities in 2020 and beyond. Results of the Annual ZKI Survey on Trends at Academic IT Centres
}

\author{
Malte Dreyer and Maik Bierwirth ${ }^{1}$ \\ both Humboldt University of Berlin, Germany \\ malte.dreyer@hu-berlin.de maik.bierwirth@hu-berlin.de
}

\begin{abstract}
Academic IT centres throughout Europe and beyond were affected heavily by the consequences of the Covid-19 pandemic. In particular, teaching services and video conferencing tools had to be significantly enhanced and scaled immediately, while the impact on research IT was moderate, in comparison. In addition, after the Schrems II ruling of the European Court of Justice in July 2020, the situation was further complicated by the fact that the EU-US Privacy Shield was declared invalid. Therefore, tools and services by IT companies based in the US can hardly be used at state-funded universities in the EU without substantial negotiations with the vendors.

A survey across 94 academic institutions in Germany shows which aspects stand out and what priorities many of the German IT centres have set for this sudden, inevitable surge in digitalisation in 2020. The working group on "Strategy and Organisation" of the ZKI Association for German academic IT centres conducts an annual survey on the most important topics and focal points of member institutions. The survey takes up and documents the most relevant or trending issues of IT facilities from universities and research institutions. It is completed by CIOs, heads of data centres, IT directors and persons in comparable roles. The 2021 survey, carried out in December 2020 and January 2021, had an additional focus on the impact of the Covid-19 pandemic on IT institutions in 2020. The results might also shed light on the effects of the pandemic on academic IT facilities in other EU countries - or serve as a basis for differentiation.
\end{abstract}

The annual ZKI survey on trends at German academic IT centres is conducted since 2018. The number of participants has grown constantly over the years - with 94 academic institutions having completed

${ }^{1}$ ORCID-iDs: https://orcid.org/0000-0002-1775-8622 and https://orcid.org/0000-0003-1042-6702. 
the questionnaire of the current fourth survey carried out from December 2020 to January $2021 .^{2}$ For this 2021 edition of the survey, seven additional questions were included in the questionnaire under the separate heading "Focus topic: Impact of the pandemic on IT institutions". These questions about the impact "on teaching services and technologies" or "home office support" were answered by more than half of the participants, which still gives quite an overview on the most relevant effects. The core survey with its more basic questions was completed by 80 to 90 institutions, on the average.

Overall, the results of the survey show an enormous acceleration in the implementation of new projects in IT institutions. Many institutions expect this trend to continue even after the end of the pandemic. The responses reveal a clear tension between the rapid provision of new services from the cloud, the compliance requirements of data protection and information security, and the resource requirements for on-site operations. In previous years, such strategic considerations on sourcing and operational architecture were hardly addressed. However, in this year's survey responses, these aspects are mentioned in almost all question categories.

The top trends in 2021 for the ZKI community are the topics:

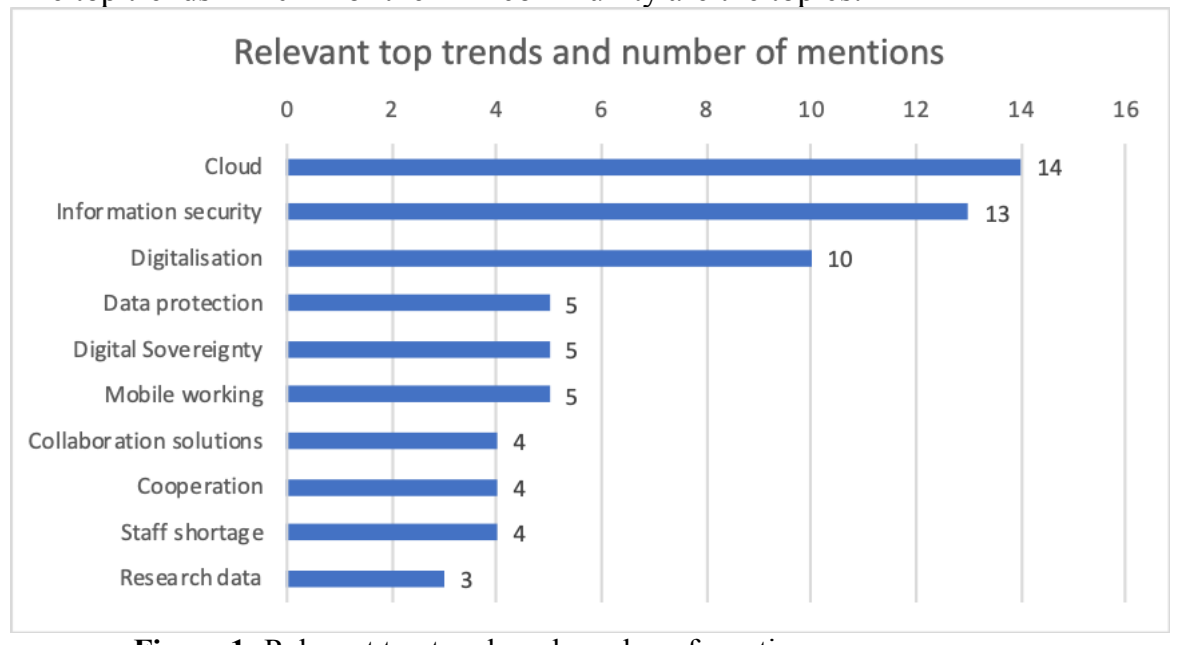

Figure 1: Relevant top trends and number of mentions

The survey asks on the one hand about general IT trends and on the other about trends that are particularly relevant for one's own institution (cf. Fig. 1). Among the general trends, the topics "cloud", "digitalisation" and "information security" are the top mentions - followed by "machine learning" and the topics "mobile working" and "digital sovereignty". The trends that are particularly relevant for the answering IT centres themselves are mostly identical, except for the topic of "machine learning", which generally appears in fourth place as a trend, but only in eleventh place among the topics in terms of relevance for the own institution. Instead, the topics "data protection" and "collaboration solutions" are also mentioned. "Digital sovereignty", "mobile working" and "collaboration solutions" had not previously been indicated as a trend in any of the ZKI Top Trends surveys and can therefore also be

${ }^{2}$ Cf. Malte Dreyer (2021): Ergebnisse der ZKI Top-Trends-Umfrage des ZKI-Arbeitskreises Strategie und Organisation für das Jahr 2021. https://doi.org/10.5281/zenodo.4530714.

For English version see Malte Dreyer (2021), Results of the ZKI Top Trends Survey of the ZKI Strategy and Organisation Working Group for 2021: http://doi.org/10.5281/zenodo.4775116.

See also for comparison: Malte Dreyer (2020). Ergebnisse der ZKI Top-Trends-Umfrage des ZKI-Arbeitskreises Strategie und Organisation für das Jahr 2020. http://doi.org/10.5281/zenodo.3666168.

The HIS-Institut für Hochschulentwicklung (HIS-HE, institute for the development of higher education) conducted a more general survey among university leadership on the effects of the Covid-19 pandemic: Elke Bosse et al (2020): Corona@Hochschule - Befragung von Hochschulen zur (digitalen) Lehre. Download: $\underline{\text { https:/his- }}$ he.de/publikationen/detail/coronahochschule. 
seen as direct effects of the pandemic. Particularly in context of the Schrems II ruling of the European Court of Justice from July 2020, "digital sovereignty"3 is understood to mean a complete reassessment of fundamental strategies of IT centres for the portfolio, procurement, configuration, compliance and operation.

Most higher education institutions have substantially enhanced the systems for online teaching and established new services during the last year. The IT facilities have taken on much more extensive tasks than before, especially in the areas of support and communication. Also, the rapid expansion of services and scaling has brought information security and data protection even further into focus. This has also led to improved cooperation in these areas.

The increased interest in the services is also accompanied by a higher expectation of the quality of the services and a closer exchange with the users. These effects have led to a clear dynamisation of digitalisation at the institutions. The extensive ad-hoc digitalisations could already be consolidated in approx. $37 \%$ of the institutions. In contrast, most institutions report no or only moderate effects of the pandemic on research IT. In some cases, higher demand is mentioned in the areas of research data management, high-performance computing and machine learning.

The services for working from home were expanded and new hardware, especially notebooks, was procured. In some cases, a new client management architecture and security concepts were developed for mobile working. Due to the increased effort for training and support, personnel bottlenecks in these areas have become more visible. Overall, it is emphasised that home office works well - even in areas where it seemed unthinkable before. Through online collaboration, the interaction between employees has changed in a predominantly positive way. They report more communication, more efficient meetings, more creativity, fewer concerns and more structured project management. On the other hand, leadership and management are described as more time-consuming and difficult.

Most universities have extensively enhanced their own systems for online teaching. Not only have many new services been put into operation, but existing services have also been scaled and expanded for intensified use. Video conferencing systems are mentioned here most frequently. Specified by name are the solutions BigBlueButton, Flowcast, Jitsi, Microsoft Teams, Matrix, Nextcloud Talk, OnlyOffice, OpenCast Studio, Overleaf, RocketChat, Seafile, Cisco WebEx and Zoom. The strategy for these systems will be re-evaluated in many institutions after the pandemic. Most academic IT facilities also indicate to operate two or more video conferencing systems for different scenarios.

The most relevant aspects with regard to teaching services and technologies:

\begin{tabular}{|l|c|}
\hline Most frequent mentions & Mentions \\
\hline Scaling of the services & 15 \\
\hline Online teaching & 14 \\
\hline Video conferencing systems & 10 \\
\hline Many new services & 8 \\
\hline More support and communication & 7 \\
\hline Dynamisation of digitalisation & 6 \\
\hline
\end{tabular}

\footnotetext{
${ }^{3}$ Even independently of the Schrems II ruling, the topic of digital sovereignty or 'strategic autonomy' is of growing interest in Germany and even more so with regard to the European Union.

Cf. Gabriele Goldacker (2017): Digitale Souveränität [White paper of Kompetenzzentrum Öffentliche IT (ÖFIT)]. https://www.oeffentliche-it.de/documents/10181/14412/Digitale+Souveränität; Resa Mohabbat Kar, Basanta E. P. Thapa (2020): Digitale Souveränität als strategische Autonomie - Umgang mit Abhängigkeiten im digitalen Staat [White paper of ÖFIT]. https://www.oeffentliche-it.de/documents/10181/14412/Digitale+Souveränität+als+strategische+Autonomie++Umgang + mit+Abhängigkeiten+im+digitalen+Staat; Henning Kagermann, Karl-Heinz Streibich, Katrin Suder (2021): Digital Sovereignty - Status Quo and Perspectives [Acatech Impulse Paper, available in German, English and French]. Download: https://www.acatech.de/publikation/digitale-souveraenitaet-status-quo-und-handlungsfelder/.
} 


\begin{tabular}{|l|l|}
\hline Contact tracing & 4 \\
\hline Burdens for staff & 3 \\
\hline Digital collaboration & 3 \\
\hline Services for online exams & 3 \\
\hline Lecture recording & 3 \\
\hline
\end{tabular}

Table 1: Impact on teaching services and technologies

The effort for support and communication has increased considerably for the IT centres. Examples mentioned in this context are the intensified debates on data protection and IT security issues as well as generally broader discussions on services and the capabilities of platforms. The increased use of services is also accompanied by increased demands on the quality of service provision. Completely new services were developed for contact tracing ${ }^{4}$ in presence and hybrid mode, whereby the universities are pursuing very different approaches to implementation. Furthermore, collaboration solutions, services for online exams and video recordings are mentioned. At large, a clear dynamisation of digitisation at the IT facilities and a lot of time pressure overall are reported, which has also led to a considerable additional workload for staff. In addition to the many services to be established and expanded, the ECJ ruling Schrems II has brought about significant changes. The institutions are reviewing their own services in this regard, reassessing and describing fundamental effects on sourcing and operating strategies. In this context, a significant increase in the workload for coordinating security concepts and data processing agreements is reported, as well as a professionalisation of processes.

\section{Focus 2021: Impact of the pandemic on IT facilities}

For the year 2021, an additional survey focus was introduced on the impact of the pandemic on IT facilities. Seven questions specifically addressed the consequences of the Covid-19 pandemic on higher education and in particular on academic IT facilities and their tasks. The questions comprise:

- What impact has there been on teaching services and technologies?

- What was the impact on services for research IT?

- What impact has there been in terms of home office support?

- What has changed in the interaction of the employees in your institution?

- Could the ad-hoc digitalisations be consolidated?

- What is your strategy regarding video conferencing solutions?

- How do you deal with the ECJ ruling Schrems II? What effects does the ruling have on you?

The questions were answered by 40 to 51 of the participants in the survey. Unlike the vast expansion of services and systems for online teaching (as shown in the table above), the impact on research IT was only minor or moderate. However, the provision of secure access from outside the HEIs and more support activities are mentioned. Some HEIs also report an increase in requests for research data management, high performance computing and machine learning. There are also isolated reports of needs for support for digital events and special collaboration solutions. Jitsi, Nextcloud, OnlyOffice and Cisco WebEx are mentioned as newly provided services in this context. The following table summarizes the results:

\footnotetext{
${ }^{4}$ See also Malte Dreyer, Hartmut Hotzel (2020): Umfrage zum Thema Kontaktverfolgung an Hochschulen im September 2020 durch den ZKI-Arbeitskreis Strategie \& Organisation. http://doi.org/10.5281/zenodo.4045311
} 


\begin{tabular}{|l|c|}
\hline Most frequent mentions & Frequency \\
\hline Little to none & 22 \\
\hline Secure remote access & 3 \\
\hline More support & 2 \\
\hline Services for collaboration & 2 \\
\hline
\end{tabular}

Table 2: Impact on research IT

Support for home office had an enormous increase in demand, especially in the first months of the pandemic. The focus of the impact was on the procurement of hardware, notebooks and other devices for use from home. To support the increased access from outside the university, VPN capacities were expanded at many universities. In general, capacities, licences and information for the services used in home office were also massively increased. In some cases, completely new architecture and security concepts for working in home office and for mobile working in general have been created and implemented in order to be able to access the administrative systems more flexibly. ${ }^{5}$ In this context, security issues for access to data with a high protection requirement and unresolved issues for access through private devices as well as missing establishment agreements on teleworking are described.

Due to the scope of the measures and the amount of hardware procured, the workload of the IT facilities for training and support has increased a lot. Here, staff bottlenecks have become more visible than in times of lower load. Many processes have been switched to online procedures. However, it is emphasized that home office works well - even in areas where it was inconceivable before.

\begin{tabular}{|l|c|}
\hline Most frequent mentions & Frequency \\
\hline Training and support & 9 \\
\hline VPN expansion & 8 \\
\hline Procurement of notebooks & 6 \\
\hline Notebook output & 5 \\
\hline More home office workplaces & 4 \\
\hline Hardware procurement & 3 \\
\hline Devices for home office are missing & 3 \\
\hline Many new services & 3 \\
\hline Zoom & 3 \\
\hline
\end{tabular}

Table 3: Impact on home office support

The collaboration between employees faced certain challenges but also provided many opportunities for improvement. Thus, the answers to this question are partly contradictory. The majority describe more and better communication, better collaboration, fast communication channels and an improvement in the meeting culture as well as more focused meetings. In addition to video conferencing as a basis, the use of other tools and methods for project management is generally indicated as a necessary condition for success, with open source solutions gaining more recognition than before the pandemic. More meetings, more emails, communication via chats as well as more creativity and ad-hoc communication are mentioned as answers combined with fewer concerns and a great commitment by the employees. Digital systems are also described as operational for conducting interviews, with the onboarding and training of new employees in particular being specified as a distinct problem area and

\footnotetext{
${ }^{5}$ See also Dreyer, Malte. (2020). Kurzumfrage zur Situation der Digitalen Angebote für Lehre und Home-Office im April 2020 durch den ZKI-Arbeitskreis Strategie \& Organisation und die AMH [Brief survey on the situation of digital offers for teaching and home office in April 2020]. http://doi.org/10.5281/zenodo.3826557.
} 
challenge when contact and exchange are purely digital. In this context, the use of digital tools is described as an easy prerequisite and as an elementary step towards digitalisation.

On the other hand, individual responses report more effort for leadership and coordination, longer coordination paths and a general slowdown. Leadership is generally perceived as more difficult in some responses and a tendency of crossing boundaries in communication is named as a problem. In addition, it is noted that the initially stronger overlapping cooperation has decreased again in the course of the pandemic. Other negative effects stated by participants in the survey include less spontaneous communication, fewer breaks, more difficult communication and a lack of short conversations around meetings.

\begin{tabular}{|l|c|}
\hline Most frequent mentions & Frequency \\
\hline More digital communication & 11 \\
\hline More meetings & 7 \\
\hline Cooperation has improved & 6 \\
\hline More ad-hoc communication & 5 \\
\hline Processes were accelerated & 3 \\
\hline On-Boarding of new employees is more difficult & 2 \\
\hline More project management & 2 \\
\hline Leap into digitalisation & 2 \\
\hline Interpersonal issues recede into the background & 2 \\
\hline
\end{tabular}

Table 4: Impact on internal communication and collaboration

Especially for academic IT facilities, the pandemic meant an instant boost of digital tools and services they had to implement in almost no time during March and April 2020. Less than a year later, according to the survey's answers, $37 \%$ of the ad-hoc digitisation measures have already been made permanent. A further $37 \%$ of the responses indicate partial consolidation and $26 \%$ report that the measures have not yet been consolidated in any way.

For the partial continuations, limitation to teaching or the purely technical aspects such as the financing of licences or IT systems are reported. Concerning staffing in general and finding the right skills on the labour market, the survey responses mention the general shortage of IT staff in the labour market, which has even increased since the pandemic.

Some responses describe an intended analysis of the measures planned for 2021 or for the time after the pandemic, which should precede the continuation considerations and in which the changed framework conditions - such as higher security requirements, questions of digital sovereignty or lower online quotas for teaching in regular operation - will also be included in the evaluation. In this regard, many responses assume the working conditions will have changed permanently after the pandemic and won't return to the previous forms of work. Consolidation of ad-hoc digitisations:

\begin{tabular}{|l|c|}
\hline Most frequent mentions & Frequency \\
\hline Yes & 16 \\
\hline No & 11 \\
\hline Partial & 10 \\
\hline No additional staff & 3 \\
\hline Teaching area only & 3 \\
\hline Technical only & 2 \\
\hline
\end{tabular}

Table 5: Consolidation of ad-hoc digitisations 
Video conferencing technologies are the central building block for communication during the pandemic. ${ }^{6}$ Most participants report having or planning to use two or more systems for video conferencing - often with one solution of these in on-site operation. Several feedbacks emphasise the plan to re-evaluate the strategy for video conferencing solutions after the end of the pandemic. Reasons given for using several systems collaterally include problems with large conferences, lack of acceptance for non-commercial systems, security classifications for sensitive communication processes and the trustworthiness of systems. End-to-end encryption and pseudonymisation of user data are mentioned as measures to maintain the operation of US providers. Some survey participants report an increase in requirements due to hybrid scenarios and specific needs from teaching, which necessitates a reevaluation of the products used. The changed requirements are to be assessed through surveys among university members.

Initiatives to acquire joint licences or to set up a state-wide cloud solution for videoconferencing are mentioned by some federal states. Other responses report specific expectations towards the DFN-Verein - the NREN 'German research network', which also offers an own video conferencing tool - to provide a suitable solution for all universities.

\begin{tabular}{|l|c|}
\hline Most frequent mentions & Frequency \\
\hline Two systems in use & 21 \\
\hline More operation on site & 6 \\
\hline Multiple systems & 5 \\
\hline Security classification for videoconferencing & 4 \\
\hline Reassessment after the end of the pandemic & 3 \\
\hline BigBlueButton and commercial solution & 2 \\
\hline Search for an integrated solution for everything & 2 \\
\hline
\end{tabular}

Table 6: Strategy for video conferencing tools

The ECJ ruling Schrems II does not directly refer to consequences of the Covid-19 pandemic, yet it proves highly relevant in the context of all the ad-hoc digitalisations and new IT services implemented in the context of the pandemic. To enable the digital semester in 2020, IT facilities had to implement solutions for video conferencing and digital teaching that were at once available, robust and - another important criterion - scalable for bigger user groups.

However, on July 16, 2020, close to the end of the summer semester in Germany, the European Court of Justice declared the EU-US Privacy Shield invalid in their ruling „Schrems II“" (named after Austrian data privacy activist Max Schrems, who had filed the lawsuit). The ECJ ruled: With regard to the access rights of the US authorities, the data protection requirements that apply in the EU are not guaranteed. The immediate consequences for IT centers are still quite unclear and the exceptional situation of the pandemic inevitably led to a pragmatic approach toward the ad-hoc digitalisation and the necessary licencing of IT services. Still, once the HE institutions go back to on-site teaching, all digital solutions that students, teachers and other employees now are used to, might have to be revised with regard to the new status quo in the EU legal framework for data protection.

There were 45 responses to the two-part survey question 'How do you deal with the ECJ ruling Schrems II? What effects does the ruling have on you?' The answers vary greatly. Seven respondents say they see no impact from the ruling. Others describe the review of all software and services at use as well as an evaluation of alternative products, negotiations with providers and a tendency to avoid products from US providers. In addition to increased operation of software solutions locally, more attention to the impact of the ruling in strategic considerations is also described as a consequence.

${ }^{6}$ See also Dreyer, Malte. (2020). Umfrage zu den Angeboten für Digitale Lehre an Hochschulen im Juni 2020 durch den ZKIArbeitskreis Strategie \& Organisation und die AMH. http://doi.org/10.5281/zenodo.3925120 
Some survey participants state that new contracts will only be concluded with European companies or that non-EU cloud solutions should be avoided. The responses also mention more attention to a data-sparse configuration, stricter organisational terms of use, the pseudonymisation of data, more additional security measures and the prohibition of public clouds for sensitive data as further means. In addition, a stronger focus on the alignment of data processing agreements, security concepts and further contractual terms is stated as another consequence.

In this context, cooperation with local data protection officers is described as intensified and improved. A coordinated approach to dealing with the new situation is reported from the state of BadenWürttemberg. Due to the additional measures, a significantly higher effort for the introduction of new services is specified. On the other hand, no response mentions the shutdown of existing services due to the ruling.

Furthermore, higher education management is said to be more aware of data protection issues and the framework conditions for the use of software solutions as a result of the ruling.

\begin{tabular}{|l|c|}
\hline Most frequent mentions & Frequency \\
\hline Major uncertainties & 7 \\
\hline No effects & 7 \\
\hline Negotiations with suppliers & 6 \\
\hline Joint action in the federal state & 5 \\
\hline More coordination with data protection & 4 \\
\hline More operation on site & 3 \\
\hline Search and procurement of alternative products & 3 \\
\hline Review of all services & 3 \\
\hline Impact on strategic considerations & 2 \\
\hline Gradually adjust existing contracts & 2 \\
\hline Increased effort for the introduction of systems & 2 \\
\hline Use of the standard contractual clauses & 2 \\
\hline Testing of all systems & 2 \\
\hline Renunciation of non-EU cloud solutions & 2 \\
\hline
\end{tabular}

Table 7: Consequences of the Schrems II ruling

\section{Digital sovereignty \& best practices based on open source software}

The topic of digital sovereignty has been of interest in the German context and especially with regard to the European Union for a while already before the new ECJ ruling on data protection or the effects of the Covid-19 pandemic. The term does not only refer to aspects of IT infrastructure and data privacy but has broader layers of meaning including the individual capacities for digital literacy and aspects of risk and security management.

As a political or even economical term "digital sovereignty" describes a self-reliant industry or infrastructure avoiding unilateral structural dependence on other countries or regions. In terms of IT infrastructure, there are several aspects to it as well: Apart from judicial or ethical perspectives on data protection, the effect of vendor lock-in is to be avoided for economic reasons, too. 
In a recent impulse paper of the German Academy of Science and Engineering, acatech, the authors define eight levels of digital sovereignty with an analytical outlook on European selfsufficiency. They differentiate from the highest layer of abstraction or complexity to the most basic materials: "7) European system of laws and values -6) Software technology - 5) European data spaces - 4) Platform-as-a-Service (PaaS) - 3) Infrastructure-as-a-Service (IaaS) - 2) Communication infrastructure - 1) Components - 0) Raw materials and intermediate products". ${ }^{7}$ Quite strikingly, even though published only in March 2021 and addressing data protection issues on different levels, the paper does not refer to the Schrems II ruling or the EU-US privacy shield.

Another prominent white paper on digital sovereignty, published in September 2020, doesn't either. Unlike acatech which is also oriented at the interests of the private economic sector to some degree, the "Competence Center Public IT", short: ÖFIT, mainly focuses its attention and provides scientific analyses on IT infrastructure and digitalisation processes in the public sector. The authors of the ÖFIT white paper on digital sovereignty coin the term "strategic autonomy" as a conceptual alternative to allow for a more nuanced view. They also emphasize the necessity of a European approach. However, their analytical raster and definition of several dimensions of digital sovereignty differs significantly from the perspective of the acatech paper.

First of all, they describe the "technology bundle" with the five layers of: software, network, hardware, data and platforms. Then they distinguish seven dimensions of sovereignty that may relate

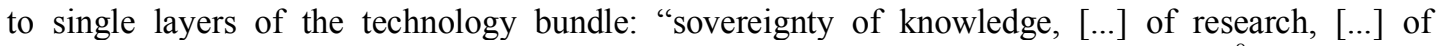
development, [...] of production, [...] of operations, [...] of use, [and] of transparency". ${ }^{8}$ Both quoted papers emphasize open-source solutions as one way to achieve a higher level of digital sovereignty.

The open-source learning management system (LMS) Moodle has been used at many HE institutions worldwide for a long time. With its high degree of interoperability, plug-in options and support of a wide range of standards, it even became an anchor for digital teaching and learning at many universities, when the Covid-19 pandemic made remote teaching and learning inevitable. The German academic Moodle community, with its broad network yet loosely organized, is about to establish a registered association in summer of 2021 to increase cooperation and coordination between all its stakeholders.

Under the name "Moodle an Hochschulen"9 (Moodle at Higher Education Institutions), the association is not only to improve networking and represent the approximately 175 German HEIs where Moodle is used, but also to commission joint developments for academic requirements in the future. In addition, the association aims to exchange and publish best practices for all Moodle topics such as didactics, support as well as setting up and operating the learning management system. Together with the already existing associations of the open-source LMS solutions ILIAS and Stud.IP, the German Moodle community has also adopted a declaration to promote open-source software in order to strengthen the use and further development of open and free educational platforms. ${ }^{10}$ These measures will also contribute to further digital sovereignty in academic teaching.

The pandemic has significantly increased the importance of video conferencing (VC) for HEIs. At the same time, the ECJ ruling "Schrems II" makes it more difficult to operate products from US video conferencing providers in a legally safe manner. In order to support strategic autonomy for universities in this field of application, many universities are taking a two-way approach, contracting a $\mathrm{VC}$ solution from a large cloud provider on the one hand and operating their own BigBlueButton instances for particularly sensitive communication processes on the other. Many HEIs see a great need to improve the security, scalability and functional depth of BBB and to make the developments of the

\footnotetext{
${ }^{7}$ Kagermann et al (2021), Digital Sovereignty, p. 10.

${ }^{8}$ Mohabbat Kar \& Thapa (2020), Digitale Souveräntität als strategische Autonomie, p. 14. (transl. M.B.)

${ }^{9} \mathrm{Cf}$. their webpage: https://moodle-an-hochschulen.de.

${ }^{10} \mathrm{Cf}$. "Freie Software für freie Lehre! Gemeinsame Erklärung der deutschen, communitygestützten Open-SourceBildungsplattformen" (May 2020), retrieved May 19, 2021, from: https://opensourcelms.de.
} 
individual universities in Germany transparent as well as to coordinate them. As a consequence, the German ZKI association established a financial framework to reinforce BBB open source developments and accelerate product improvements by means of a concerted, mutual contract with a main BBB developer in Canada. Thus, the requirements of German HEIs will be developed and integrated in updates or new versions more easily, while maintaining digital sovereignty and supporting European standards for data protection.

The exemplified actions from IT centers regarding Schrems II are illustrating an enormous change in strategy management and portfolio strategy. The effects of the ECJ ruling and in general the increase of attention to digital sovereignty lead to new developments und adjustments of the digitalisation strategies. This can be perceived as an additional result when examining the impact of the pandemic year 2020 on academic IT facilities. When comparing the general results of the ZKI surveys in 2021 and 2020, it becomes even more apparent. The most relevant new trends of the pandemic year for IT centres are data protection, digital sovereignty, mobile working and collaboration solutions. This may not be surprising, but it also indicates which topics will continue to occupy us.

\begin{tabular}{|l|l|l|l|}
\hline \multicolumn{4}{|l|}{ Relevant Top Trends - Compared Ranking 2020/2021 } \\
\hline 2021 & $1(+1)$ & 1 & Information security \\
\hline Cloud computing & $2(-1)$ & 2 & Cloud computing \\
\hline Information security & $3(=)$ & 3 & Digitalisation \\
\hline Digitalisation & $4($ new) & 4 & Machine Learning \\
\hline Data Protection & $4($ new) & 5 & Cooperation \\
\hline Digital Sovereignty & $4(n e w)$ & 6 & Personnel \\
\hline Mobile Working & $7(n e w)$ & 7 & Research data management \\
\hline Collaboration solutions & $7(-2)$ & 8 & Process management \\
\hline Cooperation & $7(-1)$ & 9 & Virtualisation \\
\hline Personnel & $10(-3)$ & & \\
\hline $\begin{array}{l}\text { Research data } \\
\text { management }\end{array}$ & $11(-7)$ & & \\
\hline Machine Learning & & & \\
\hline
\end{tabular}

Table 8: Relevant Top Trends, comparison 2020/202111

${ }^{11}$ Cf. Dreyer (2021), Results of the ZKI Top Trends Survey, p. 23. 


\section{References}

Bosse, Elke, et al (2020). Corona@Hochschule - Befragung von Hochschulen zur (digitalen) Lehre. Retrieved April 20, 2021, download from: https://his-

he.de/publikationen/detail/coronahochschule

Dreyer, Malte (2021). Ergebnisse der ZKI Top-Trends-Umfrage des ZKI-Arbeitskreises Strategie und Organisation für das Jahr 2021. https://doi.org/10.5281/zenodo.4530714

Dreyer, Malte (2021). Results of the ZKI Top Trends Survey of the ZKI Strategy and Organisation Working Group for 2021. http://doi.org/10.5281/zenodo.4775116

Dreyer, Malte (2020). Ergebnisse der ZKI Top-Trends-Umfrage des ZKI-Arbeitskreises Strategie und Organisation für das Jahr 2020. http://doi.org/10.5281/zenodo.3666168

Dreyer, Malte. (2020). Kurzumfrage zur Situation der Digitalen Angebote für Lehre und HomeOffice im April 2020 durch den ZKI-Arbeitskreis Strategie \& Organisation und die AMH. http://doi.org/10.5281/zenodo.3826557

Dreyer, Malte. (2020). Umfrage zu den Angeboten für Digitale Lehre an Hochschulen im Juni 2020 durch den ZKI-Arbeitskreis Strategie \& Organisation und die AMH. http://doi.org/10.5281/zenodo.3925120

Dreyer, Malte, \& Hotzel, Hartmut (2020). Umfrage zum Thema Kontaktverfolgung an Hochschulen im September 2020 durch den ZKI-Arbeitskreis Strategie \& Organisation. http://doi.org/10.5281/zenodo.4045311

"Freie Software für freie Lehre! Gemeinsame Erklärung der deutschen, communitygestützten Open-Source-Bildungsplattformen” (May 2020). Retrieved May 19, 2021, from: https://opensourcelms.de

Goldacker, Gabriele (2017). Digitale Souveränität [White paper of Kompetenzzentrum Öffentliche IT (ÖFIT)]. Retrieved April 20, 2021, from: https://www.oeffentlicheit.de/documents/10181/14412/Digitale+Souveränität

Kagermann, Henning, Streibich, Karl-Heinz, \& Suder, Katrin (2021): Digital Sovereignty Status Quo and Perspectives [Acatech Impulse Paper]. Retrieved April 20, 2021, download from: https://www.acatech.de/publikation/digitale-souveraenitaet-status-quo-und-handlungsfelder/

Mohabbat Kar, Resa \& Thapa, Basanta E. P. (2020): Digitale Souveränität als strategische Autonomie - Umgang mit Abhängigkeiten im digitalen Staat [White paper of ÖFIT]. Retrieved April 20, 2021, from: https://www.oeffentlicheit.de/documents/10181/14412/Digitale+Souveränität+als+strategische+Autonomie++ Umgang + mit + Abhängigkeiten + im + digitalen + Staat 


\section{Author biographies}

Malte Dreyer is the director of the IT centre (CMS - Computer and Media Service) of HumboldtUniversität zu Berlin, Germany. Before he was director for the department of research and development at Max Planck Society, Max Planck Digital Library. He designed and developed research and publication data infrastructure for the Max Planck Society's institutes, as well as many research tools. Providing advice on software and information architecture, he is a member of several technical boards. Malte Dreyer's interests now are in the field of compliance and risk management, scalable information management architectures and infrastructures in the intersection of organizational perspectives on ICT from data centers and information management organizations. Current projects are in the fields of flexible sourcing strategies, compliance management, linguistics and research services management.

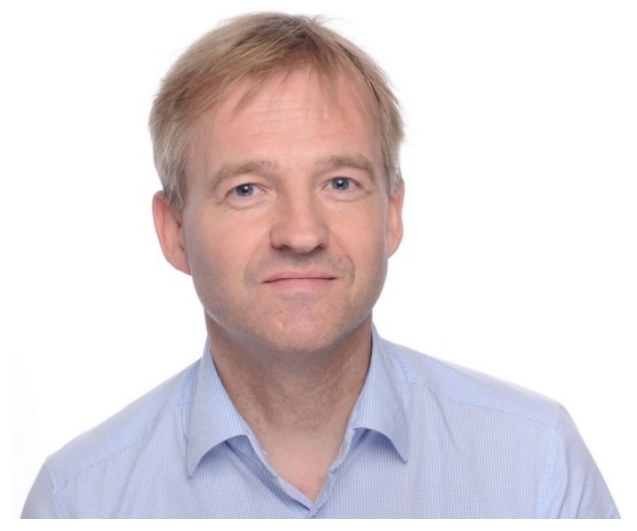

Dr. Maik Bierwirth is responsible for project development and third-party funding proposals at the Computer and Media Service of Humboldt-Universität zu Berlin, Germany. Before he worked in academic publishing, copyediting and cultural criticism. He obtained his doctorate in the humanities in the interdisciplinary graduate research programme "Automatisms. The emergence of structures beyond planned processes in culture, media and information technology" at the University of Paderborn. Current projects are in the fields of research data management, research services, information management, scholarly communication and digital sovereignty.

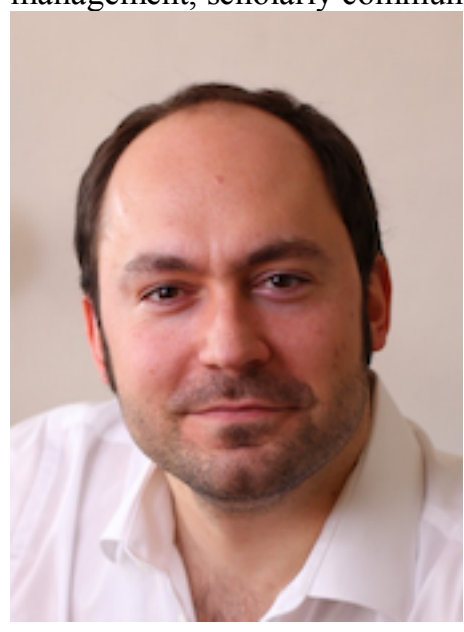

